\title{
AnOnYmous nas manifestações de JUnHO: Uma PROPOSTA TEÓRIOA
}

\author{
Michele Caroline Torinelli ${ }^{173}$ \\ Ana Luisa Fayet Sallas ${ }^{174}$
}

Resumo: Uma máscara se destacou nos protestos de junho de 2013 no Brasil. Tratase do símbolo dos Anonymous, uma rede que não se identifica como grupo ou movimento, mas como uma ideia. A máscara pode ser vista em registros de manifestações ao redor do globo: desde mobilizações no norte da África a partir de 2011, passando por diversos outros países. Além de ter sua máscara-símbolo amplamente adotada, eles atuaram como importantes mediadores dos protestos brasileiros de junho de 2013. Entende-se aqui que essa atuação não é um evento isolado, mas insere-se num processo que envolve transformações culturais nos âmbitos de juventude, comunicação e política - aspectos que dialogam entre si e convergem na aplicação do conceito de rede à situação pesquisada. Trata-se de delinear as bases para a investigação do significado sociopolítico da atuação dos Anonymous nas manifestações de junho, sob uma perspectiva de movimentos sociais em rede que integra comunicação, cultura e política.

Palavras-chave: Anonymous. Movimentos sociais em rede. Cultura política.

\section{INTRODUÇÃO}

Brasil, junho de 2013. A tarifa de ônibus sobe nas maiores cidades do país. O Movimento Passe Livre, que já contava com uma trajetória de quase uma década tendo protagonizado relevantes manifestações em anos anteriores em Florianópolis e Salvador - convoca protestos ao redor do Brasil. Manifestações na cidade de São Paulo já alcançavam milhares de participantes na primeira dezena do mês, quando no dia 13 o uso da violência por parte da Polícia Militar choca o país. Desencadeia-se uma onda de manifestações massivas protagonizadas por jovens que extrapolam a pauta do transporte, com reivindicações difusas, mobilizadas digitalmente e

173 Michele Caroline Torinelli é mestranda em Sociologia pela Universidade Federal do Paraná na linha de pesquisa de Cultura, Comunicação e Sociabilidades com a temática de Juventude: Cultura e Participação.

174 Ana Luisa Fayet Sallas realizou pós-doutorado no ano de 2012 no Colégio do México, México. Concluiu o Doutorado em História pela Universidade Federal do Paraná em 1998 e o Mestrado em Antropologia Social pela Universidade de Brasília em 1987. Atualmente é Professora Titular do Departamento de Sociologia da Universidade Federal do Paraná. 
divulgadas em tempo real pelas mídias sociais, de modo a surpreender as instituições políticas e seus representantes, assim como a imprensa e a população em geral, devido à sua amplitude, densidade e ao seu caráter de novidade. (GOHN, 2013; MARICATO et al, 2013; MALINI, 2013a).

Nas manifestações que se seguiram, bem como nas repercussões em fotos, matérias e vídeos na mídia de massa e nas redes sociais digitais, um elemento destacou-se: a máscara de Guy Fawkes, adereço emblemático da História em Quadrinhos (HQ) V de Vingança (MOORE, LLOYD, 2006), posteriormente transformada em filme homônimo (2006) ${ }^{175}$. A quase onipresente máscara é o símbolo adotado pelos Anonymous. Similarmente às manifestações, eles não possuem líderes explícitos ou pautas específicas. Aliás, nem se denominam um movimento, mas uma ideia, um conceito (ANONYMOUS). Seu universo de organização é majoritariamente digital e seu papel se destaca não só no Brasil, mas em manifestações e ações ao redor do mundo (MACHADO, 2013).

Segundo a proposta de investigação aqui apresentada, a atuação dos Anonymous nas manifestações de junho ${ }^{176}$ não é um evento isolado, mas insere-se num processo que envolve transformações culturais nos âmbitos de juventude, comunicação e política - aspectos que dialogam entre si e convergem na aplicação do conceito de rede à situação pesquisada. Trata-se de delinear as bases para a investigação do significado sociopolítico ${ }^{177}$ da atuação dos Anonymous nas manifestações de junho, sob uma perspectiva que trata de movimentos sociais em rede (CASTELLS, 2013) integrando comunicação, cultura e política.

\section{ANONYMOUS NO BRASIL E OS PROTESTOS DE JUNHO DE 2013}

175 O filme baseou-se na HQ desenvolvida por Moore e Lloyd (2006) na década de 1980, que por sua vez inspirou-se na trajetória de Guy Fawkes, católico inglês que tentou explodir o parlamento de seu país em 1605, com o rei James I dentro, no que ficou conhecido como "Conspiração da Pólvora". Ele foi impedido e condenado à forca. (FEBBRO, 2012).

176 As manifestações de junho de 2013 no Brasil serão indicadas apenas como "manifestações de junho". Apesar de ter sido essa a opção da presente pesquisa, outras denominações surgiram, tais como "Jornadas de Junho" (MALINI, 2013b; MARICATO et al, 2013).

177 Acredita-se que, "além do marco das 'democracias realmente existentes', é necessário observar em que medida os movimentos sociais adotam referências, geram discursos e criam práticas espaciais de resistência, nas quais a democracia aparece como uma criação coletiva, como a instituição de um novo imaginário, de tensão permanente entre projetos e territorialidades." (BRINGEL, ECHART, 2008, p. 467). 
A rede Anonymous originou-se nos primeiros anos do século XXI num fórum na internet ${ }^{178}$ no qual jovens compartilhavam bizarrices. A maioria dos usuários identificava-se simplesmente como anônimo (anonymous, em inglês), o que fazia parte da dinâmica de relacionamento no fórum. Quando sofreram ameaças da igreja de Cientologia de serem processados por escrachar, nas redes digitais, um vídeo com Tom Cruise falando das crenças da igreja (que a instituição afirmaria tratar de conteúdo interno), eles "derrubaram"179 seu site (entre outras ações tal como ligações telefônicas em massa para interditar os canais de comunicação da igreja). A partir disso os até então anônimos digitais encontraram-se presencialmente pela primeira vez para protestar em diversos locais ao redor do planeta em 2008 contra a "caça" que se instaurou contra eles a partir desse caso, o que corroborou para a consolidação da rede sob uma perspectiva política. Entre outras iniciativas dos Anonymous, destaca-se uma ação levada a cabo em 2011, quando foram responsáveis por "derrubar" as plataformas de pagamento online da Visa, Mastercard e Paypal em protesto contra a atitude dessas empresas de bloquear doações para o Wikileaks. (MACHADO, 2012a; 2013; COLEMAN, 2011; WE ARE LEGION, 2012).

"Nós não somos uma organização e não temos líderes. Oficialmente nós não existimos e não queremos existir oficialmente. Nós não seguimos partidos políticos, orientações religiosas, interesses econômicos e nem ideologias de quaisquer espécies", informa a página digital Anonymous Brasil. Mais do que um movimento, acredita-se tratar de uma cultura comum, que se forja principalmente nos ambientes digitais e entre jovens em escala mundial (WE ARE LEGION, 2012; COLEMAN, 2011; MACHADO, 2013).

Durante as manifestações de junho, eles "derrubaram" páginas virtuais como do Partido do Movimento Democrático Brasileiro (PMDB) e da Secretaria da Educação do Estado de São Paulo -, hackearam contas em mídias sociais da presidente Dilma Rousseff e da revista Veja, identificando-se como "Anonymous" ou "Anons" e incitando as manifestações, e vazaram documentos da Polícia Militar e da

178 Trata-se de uma página do 4chain denominada $b$ : <http://boards.4chan.org/b/> .

179 Costuma-se "derrubar" uma página digital por meio de ações distribuídas de negação de serviço (DDoS - Distributed Denial of Service), que consistem "em acessar repetidas vezes determinado servidor de maneira tal, que este acaba por não suportar a sobrecarga. Com isso, ele para de oferecer seus serviços." (MACHADO, 2012a). 
Confederação Brasileira de Futebol (CBF). Uma cartografia digital acerca das manifestações, que partiu das mensagens publicadas no Facebook no dia 13 de junho, identificou que das cinco páginas que mais geraram repercussão nessa data, três estão relacionadas aos Anonymous (INTERAGENTES, 2013).

A partir disso, é preciso levar em conta em que medida a atuação dos Anonymous nas manifestações de junho remete a hacktivismo ${ }^{180}$ ou ativismo online ${ }^{181}$ (entendido como sinônimo de ciberativismo), sendo que, além de empreender ações de hacking, destacaram-se como mobilizadores e divulgadores dos protestos ${ }^{182}$. Entretanto, o enfoque da pesquisa não se centrará no aspecto hacker (apesar de ser impossível ignorá-lo, por fazer parte da constituição dos Anonymous), mas no papel de mediação e símbolo que assumiram durante as manifestações de junho, e como sua atuação digital se combinou com a dinâmica das ruas.

É importante destacar que a atuação dos Anonymous, assim como as manifestações de junho em si, fazem parte de um contexto global. Movimentos que surgiram no norte da África em 2011, se espalharam por outros continentes e se desdobram até o momento têm em comum a emergência de um ativismo político de características horizontais protagonizado por jovens que ocupa os espaços públicos e se utiliza de tecnologias digitais para se articular em redes, de forma a ampliar sua atuação nas ruas e questionar a política institucional vigente. (HARVEY et al, 2012; GOHN, 2013; MARICATO et al, 2013; CASTELLS, 2013).

\section{A MÁSCARA E A MULTIDÃo}

A simbologia da máscara, o caráter carnavalesco das manifestações de junho e o conceito de multidão são abordagens nas quais se apoiará a investigação do imaginário que constitui a ideia Anonymous e sua relação com o formato das

180 "Para um dos principais coletivos de hacktivistas, autodenominado Cult of the Dead Cow [...] hacktivismo [é] uma prática de hacking, phreaking ou de criar tecnologias para alcançar um objetivo social ou político." (SILVEIRA, 2010, p. 32). Já phreaking é um espécie de hacking no âmbito telefônico.

181 De acordo com Machado (2013, p. 44), ativismo online consiste em "disseminação de informações, publicação de cartas-protesto, envio em massa de e-mails, blogagem coletiva -, que raramente envolve as habilidades presentes no hacking de computador".

182 Machado (2013, p. 29) sugere que os Anonymous se engajam politicamente de quatro formas principais: "promovendo o anonimato; evangelizando; formando redes distribuídas; exibindo e possibilitando várias formas de ações políticas." 
manifestações de junho. Tal análise implica em explorar a dinâmica da atuação dos Anonymous entre o meio material (nas ruas) e o meio digital durante os protestos de junho e seu movimento de enfrentamento e cooptação frente ao status quo.

A máscara é o embuste, o disfarce, o artefato de carnaval - festa na qual não importa seu nome ou quem é você, mas como você age. É elemento cênico, de brincadeiras e conexão com o imaginário, adereço de vilões e heróis, que facilita a libertação do indivíduo frente aos papeis sociais. "Anota aí, eu sou ninguém", disse uma integrante do Movimento Passe Livre em entrevista sobre as manifestações de junho (PELBART, 2013), numa postura que poderia ser de $V$, o protagonista mascarado de $V$ de Vingança. Ao mesmo tempo em que permite ser ninguém, a máscara possibilita ser todos183 - como proclama Subcomandante Marcos, portavoz do EZLN - Exército Zapatista de Libertação Nacional (MACHADO, 2012b)184. Seguindo a perspectiva de Bakhtin, Martín-Barbero (2003, p. 107-8) identifica o potencial subversivo da ocupação das ruas pela cultura popular no carnaval, primeiramente por meio do riso, mas principalmente através da máscara:

A máscara, outro dispositivo do cômico e do carnaval, exprime ainda mais plenamente a negação da identidade como univocidade. A máscara está na mesma linha de operação que [...] os apelidos: ocultação, violação, ridicularização da identidade, e ao mesmo tempo realiza o movimento das metamorfoses e as reencarnações, que são o movimento da vida. Mas a máscara joga também sobre um outro registro de sentido, é estratégia de encobrimento e dissimulação, de engano da autoridade e inversão das hierarquias.

Gutiérrez (2013) aponta para o aspecto carnavalesco que assumem os protestos no Brasil, caracterizado não só pela máscara, mas também pela alegria, pela chacota e pela ocupação do espaço público, que consistem em formas de

183 A simbologia da máscara é essencial para investigar a identidade nos Anonymous que, segundo Machado (2013, p. 93), "consiste em relegar momentaneamente a segundo plano sua identidade. Isso significa que a identificação com os Anonymous implica adotar uma identidade coletiva e pretensamente consensual em detrimento das próprias individualidades de seus apoiadores. [...] por um lado, todos fazem parte da ideia Anonymous e, em tese, contam com uma voz ativa sobre ela. Por outro, no entanto, ninguém está habilitado a falar em nome dela, muito menos a representá-la de alguma forma. Por isso, quando colocam a máscara que imita o rosto de Guy Fawkes, os rostos por trás dela são sobrepujados por todo o ideário por ela carregado. Não obstante, ela valeria muito pouco sem essa atuante multiplicidade de rostos."

184 Silveira (2010, p. 32) indica que o EZLN também está na origem do que denomina desobediência civil eletrônica e hacktivismo. Segundo o autor, em 1998, "o grupo autodenominado Electronic Disturbance Theater lançou uma série de ações de desobediência civil eletrônica contra o governo mexicano, em apoio ao movimento zapatista." 
subversão e resistência política185. Segundo Chauí (2013),

Praticando a tradição do humor corrosivo que percorre as ruas, [os manifestantes] modificaram o sentido corriqueiro das palavras e do discurso conservador por meio da inversão das significações e da irreverência, indicando uma nova possibilidade de práxis política, uma brecha para repensar o poder, como escreveu um filósofo político sobre os acontecimentos de maio de 1968 na Europa.

Esta nova práxis política, para Hardt e Negri (2005), se dá por meio do "poder em rede", que é a outra face da globalização que se opõe ao Estado-nação. Os autores acreditam num projeto de democracia em escala global como potencial da multidão não hierárquica e descentralizada que ocupa as ruas. Para eles, "a multidão pode ser encarada como uma rede: uma rede aberta e em expansão na qual todas as diferenças podem ser expressas livre e igualitariamente, uma rede que proporciona meios da convergência para que possamos trabalhar e viver em comum" (ibid., p. 12).

Este conceito de multidão se contrapõe aos de povo e massa: enquanto o primeiro abarca a pluralidade, o segundo prevê unidade e o terceiro, indiferenciação. Também se contrapõe ao de classe operária, ao entender que o conceito proposto por Marx considera somente o proletariado industrial e ignora os diversos outros setores populares. Acredita-se que a produção "deve ser encarada de maneira mais ampla como produção social - não apenas a produção de bens materiais, mas também a produção de comunicações, relações e formas de vida" (ibid., p. 13). A internet serve como modelo dinâmico dessa perspectiva de rede multitudinária, pois ambas permitem constantemente novas conexões e rearranjos (ibid.).

Essa multidão que tomou as ruas em junho é composta por coletivos, redes e indivíduos que reivindicam diferentes pautas num formato que mais lembra o carnaval, com pessoas fantasiadas - entre elas as que trazem sobre a face a máscara de Guy Fawkes. Essa máscara dissimula identidades reais que se protegem da repressão (física e/ou simbólica) - tanto aquelas envolvidas com ideias de emancipação social, quanto aquelas que se apropriam desse símbolo para outros fins: o que inicialmente eram manifestações contra o aumento da tarifa do transporte público e pelo direito à cidade em alguns momentos tomaram ares fascistas (MARICATO et al, 2013).

185 Ao analisar as manifestações de junho no Brasil, Szaniecki (2013) também destaca seu caráter carnavalesco, caricato e antropofágico. 
A multiplicidade da multidão inclui não só a dinâmica de formas de organização em rede em prol do comum - mas também ideias e práticas das mais autoritárias. Além do que, todo movimento contra-hegemônico, por mais revolucionário e radical que seja, traz em si aspectos da cultura dominante186: o que vai determinar seu poder de resistência e confronto é o modo como se apropria deles, que os ressignifica (MARTíN-BARBERO, 2003). O mesmo se dá em relação ao papel das mídias (de massa e digitais em rede) nas manifestações de junho: trata-se de um ciclo de enfrentamentos e amálgamas, de afastamentos e aproximações, num processo em que a contestação da ordem vigente envolve a reprodução de alguns aspectos da ideologia dominante, que por sua vez captura a revolta em prol da manutenção do status quo - sendo, contudo, instada a assimilá-la.

\section{CULTURA DE JUVENTUdE, CULTURA DE COMUNICAÇÃo E CULTURA POLÍTICA: UMA CONVERGÊNCIA}

Ao analisar as manifestações multitudinárias, que atuam simultaneamente $\mathrm{e}$ de maneira convergente nas redes digitais e nas ruas, e se proliferam pelo planeta desde 2011, Pelbart defende que possivelmente

uma outra subjetividade política e coletiva esteja (re)nascendo, aqui e em outros pontos do planeta, para a qual carecemos de categorias. Mais insurreta, de movimento mais do que de partido, de fluxo mais do que de disciplina, de impulso mais do que de finalidades, com um poder de convocação incomum, sem que isso garanta nada, muito menos que ela se torne o novo sujeito da história. (PELBART, 2013).

O autor destaca a importância do percurso, independente dos seus resultados a curto prazo187 - e as dinâmicas de comunicação têm tido relevante papel nos processos de juventude na atualidade. Na década de 60, a juventude foi protagonista

186 Entende-se que a globalização faz com que os produtos da indústria cultural, através dos meios de comunicação de massa e da internet, cheguem a quase todos os rincões do planeta - e aqueles onde não chegam vivem à parte, relegados à invisibilidade, aquém de disputas com a civilização por estarem excluídos do cenário comunicativo global (CASTELLS, 2009).

187 Segundo Sallas e Bega (2006, P. 49), "a procura por autonomia e diferenciação, por um lado, e de cooperação e integração, por outro, não pode ser vista como expressão de processos antagônicos ou paradoxais. São apenas faces de um mesmo processo que tem marcado a vida dos jovens nas modernas sociedades industriais. Esses elementos poderiam ser pensados, aqui, como algo constitutivo da juventude, marcados por aquilo que simmel definiu como próprio de um espírito aventureiro, em que, mais do que se chegar a qualquer ponto, importa o caminho, o percurso do aventureiro." 
de intensas mudanças culturais e políticas por meio do movimento hippie e insurgências como o Maio de 68. Nessa época os jovens manifestavam uma vontade de autonomia na sociedade através de uma cultura própria, entre outras maneiras, por meio do rock. Um dos grandes diferenciais da atualidade é a apropriação das novas tecnologias da comunicação, que permitem que, mais intensamente que na década de 60 , jovens dialoguem em âmbito global.

Feixa (2000) reflete sobre como o consumo cultural e as mudanças de percepção do tempo relacionam-se com a mudança na cultura juvenil das últimas décadas (elementos que contribuem na constituição do que o autor denomina geração @) utilizando como metáfora a evolução do mecanismo que mede o tempo - o relógio - em suas versões de areia, analógica e digital. Ao contrário da primeira - originária de um período em que não havia diferenciação entre tempo e espaço e a cultura de juventude correspondia à da sociedade como um todo -, a segunda, característica da era industrial, representa uma concepção linear do tempo num momento em que a juventude passa a construir uma cultura própria de âmbito predominantemente nacional; já atualmente as tecnologias digitais permitem o deslocamento temporalespacial de maneira rápida e global, assim como o surgimento cada vez maior de micro-culturas juvenis que se prospectam, se mesclam e se reproduzem em escala planetária188.

O documentário que conta a história dos Anonymous (WE ARE LEGION, 2012) é bastante ilustrativo nesse sentido: jovens que dialogam em redes sociais digitais em escala global vão criando todo um universo de referências comuns, até mesmo uma linguagem comum, e acabam descobrindo que são muitos. Em alguns casos eram adolescentes que se sentiam solitários e, quando os Anonymous se constituíram como tal, deram-se conta de que faziam parte de uma grande comunidade. Além disso, descobriram que suas habilidades no uso das novas tecnologias, até então utilizadas basicamente para entretenimento e aprofundadas pela curiosidade, tinham poder num mundo em que os mais relevantes fluxos financeiros e comunicacionais são intermediados pelas tecnologias que eles, esses jovens, em alguma medida dominam. Assim como o personagem $V$, eles têm acesso

188 Contudo, essa juventude vive o acúmulo desses três períodos históricos - o digital se dá em continuidade e concomitantemente ao natural e ao linear (FEIXA, 2000). 
a Destino - o computador que guarda todas as informações do sistema -, e podem, em determinado aspecto, lutar de igual para igual com grandes Estados e corporações189. (ibid.; MOORE, LLOYD, 2006). A partir disso, a questão que se coloca é como esse poder é utilizado.

A postura dos Anonymous muitas vezes parece ser irresponsável (WE ARE LEGION, 2012; COLEMAN, 2011), e essa mesma crítica também é comum aos jovens que participaram das manifestações de junho. Chauí (2013) questiona nesse sentido tais movimentos em rede que tomaram as ruas do Brasil recentemente, tendo em vista as diferentes apropriações das forças das ruas que a estrutura difusa das manifestações permite:

Assinalamos anteriormente o risco de apropriação das manifestações rumo ao conservadorismo e ao autoritarismo. Só será possível evitar esse risco se os jovens manifestantes levarem em conta algumas perguntas:

1. Estão dispostos a lutar contra as ações que causam o inferno urbano, e portanto enfrentar pra valer o poder do capital de montadoras, empreiteiras e cartéis de transporte, que, como todos sabem, não se relacionam pacificamente (para dizer o mínimo) com demandas sociais?

2. Estão dispostos a abandonar a suposição de que a política se faz magicamente sem mediações institucionais?

3. Estão dispostos a se engajar na luta pela reforma política, a fim de inventar uma nova política, libertária, democrática, republicana, participativa? 4. Estão dispostos a não reduzir sua participação a um evento pontual e efêmero e a não se deixar seduzir pela imagem que deles querem produzir os meios de comunicação?

Para Pelbart (2013) parece mais plausível encarar as circunstâncias atuais como parte de um processo de empoderamento político. Por isso, antes de simplesmente descartar o potencial transformador desses jovens brasileiros, é preciso compreendê-los. Como constatou a própria Chauí (2013), mesmo que se declarem contra a política, ao ocupar as ruas e extravasar sua indignação, os manifestantes estão realizando um ato político, dizendo não ao modo como ela se dá.

De acordo com Honneth (2003), não é possível pensar os conflitos coletivos apenas sob o prisma de fins objetivos, ou de questões materiais - que são inerentes, em maior ou menor grau. Os pesquisadores costumam negligenciar que grande parte da motivação das lutas sociais se deve a "sentimentos morais de injustiça, em vez de

189 "Se o poder nas sociedades complexas se baseia cada vez mais no controle privilegiado de informação, é potencialmente um poder muito frágil, porque a simples aquisição de informação situa os atores no mesmo plano", acredita Melucci (1999, p. 91). Entretanto, não basta ter acesso às informações: é preciso (re)significá-las, ou seja, conferir-lhes sentido. 
constelações de interesses dados" (ibid., p. 255). Esses sentimentos de desrespeito são vivenciados no cotidiano, de forma individual, e se transformam em luta social a partir do momento em que se reconhece que tal experiência é típica de um grupo inteiro (ibid., p. 257).

Muitos dos jovens que tomaram as ruas não se sentem representados pelos políticos que estão no poder, sejam do partido que forem: não se sentem representados pelo sistema político (GOHN, 2013). E essa juventude, que frequentemente não encontra espaço para expressar suas opiniões na escola, na família e no sistema hegemônico como um todo (ibid.; SALLAS, BEGA, 2006) e que enfrenta um déficit de reconhecimento (HONNETH, 2003) encontrou dois espaços para extravasar sua rebeldia, que ultrapassam a tribo: a grande rede digital, na qual tribos locais podem se articular em tribos globais, e a rua ${ }^{190}$.

A juventude está exigindo seu espaço e, "como condição simbólica, adianta a possibilidade e o direito à redefinição, à variabilidade, à reversibilidade das opções de vida" (MELUCCI, 1999, p. 94), questões que dizem respeito não só aos jovens, mas à sociedade em seu conjunto. De acordo com Habermas,

\begin{abstract}
Basta tornar plausível que os atores da sociedade civil, até agora negligenciados, podem assumir um papel surpreendentemente ativo e pleno de consequências, quando tomam consciência da situação de crise. Com efeito, apesar da diminuta complexidade organizacional, da fraca capacidade de ação e das desvantagens estruturais, eles têm a chance de inverter a direção do fluxo convencional da comunicação na esfera pública e no sistema político, transformando destarte o modo de solucionar problemas de todo o sistema político. (2003, p. 115).
\end{abstract}

Diferentemente do que indica o autor, agora a desvantagem estrutural, pelo menos em um aspecto, já não é tão grande - as tecnologias digitais permitem uma reconfiguração dessa balança, o que impacta na capacidade de atuação desses atores. De forma evidente a juventude (que, apesar de contar com o protagonismo nas manifestações de junho, se articula a outros atores também negligenciados) conseguiu inverter o fluxo de comunicação de maneira eficaz, exigindo novas maneiras de solucionar velhos problemas: sem desconsiderar o poder que a mídia de massa e as instituições políticas exercem e exerceram especificamente durante os

190 Esses dois ambientes compõem uma mesma realidade (malini, 2013b) que contempla uma relação dialógica entre o digital e o material, pois "nas ruas e nas redes as formas analógicas e digitais demonstram que não são antagônicas e sim complementares" (SZANIEKI, 2013). 
protestos de junho, é preciso reconhecer que as ruas e as redes digitais também pautaram a mídia de massa e o poder público ${ }^{191}$.

\section{AÇÃO COMUNICATIVA, RECONHECIMENTO E DEMOCRACIA NOS MOVIMENTOS SOCIAIS EM REDE}

O termo "movimentos sociais em rede" é empregado por Castells (2013) para designar movimentos contemporâneos que se utilizam da internet e ocupam espaços públicos, numa contínua movimentação entre redes e ruas. Eles se conformam em redes distribuídas, sem liderança formal ou um centro de controle; conectam-se em amplitude global com outros movimentos; são autorreflexivos, pois se autoquestionam e se auto-avaliam constantemente; a indignação impulsa seu desencadeamento; não contam com programa político (exceto quando se encontram baixo regimes ditatoriais); entre outros quesitos.

Mas o que significa atuar em rede? No que tange às redes digitais, Hakim Bey já tratava do tema em 1985, quando a internet era um esboço da que conhecemos hoje, e influenciou toda uma geração de hackers e adeptos da corrente libertária. Fazendo alusão à "ética pirata", que se opunha à lógica colonialista de exploração e desenvolvia redes de colaboração nos mares interconectada por povoados costeiros e ilhas, o profeta do caos traça elementos de uma dinâmica em rede que precede a internet e se potencializa com ela.

Bey contrapõe o termo net, pelo qual designa a "internet oficial", ao termo web, uma espécie de submundo livre e criativo da internet. Ele acredita que a web seria a plataforma que propiciaria um suporte de conexão para as várias Zonas Autônomas Temporárias192, termo que cunhou para identificar experiências de emancipação similares a levantes - pois ao contrário das revoluções, que derrubam um sistema

191 Segundo análise de Pimentel e Silveira (2013), "partidos e sindicatos perderam no mês de junho o posto de intermediário privilegiado de convocação e organização de multidões, e a mídia de massas perdeu o monopólio de interpretação dos acontecimentos", o que sugere que novos intermediários se destacaram nas ruas e nos meios digitais, na esfera da política e da comunicação, tais como os Anonymous.

192 "Trata-se de uma operação anárquica de guerrilha que torna livre uma área, podendo esta ser de terra, de tempo, ou mesmo de imaginação. [...] Sua principal característica é a invisibilidade, pois o Estado não pode reconhecê-la e, com isso, destruí-la. Assim que desaparece, surge novamente noutro lugar, novamente invisível, novamente livre." (MACHADO, 2013, p. 67) 
institucionalizado e, por sua vez, institucionalizam-se também, os levantes simplesmente desconstroem a aparência de ordem do cotidiano tolhedor, geram uma mudança na percepção rumo à autonomia e depois se desfazem e se rearranjam a partir da recombinação de nós, para surgir sob outras formas em outros lugares. A potência dessas zonas, articuladas em rede, estaria justamente em não se institucionalizar, não existir oficialmente, e poder se desentrelaçar e se reagrupar em outras combinações de forma espontânea.

Pode-se aplicar essa perspectiva, analogamente, aos protestos brasileiros e aos Anonymous: os primeiros desempenharam um papel de Zona Autônoma Temporária, causando um imenso impacto simbólico, denunciando as estruturas vigentes, contudo não se institucionalizando e se dispersando novamente em diferentes redes; os Anonymous, apesar de adotarem um nome, escolheram justamente "um nome sem nome", anônimo, e recusam-se a ser chamados de grupo ou movimento - tais como as redes, sob as perspectivas de Bey e Castells, rejeitam a permanência e a estagnação e se rearranjam constantemente.

Mas antes das tecnologias digitais, as redes já se constituíam como estruturas comunicativas, mas foram subordinadas pela lógica do poder hegemônico.

Sob tais condições, redes eram uma extensão do poder concentrado no topo de organizações verticais que moldaram a história da humanidade: estados, aparatos religiosos, senhores da guerra, exércitos, burocracias, e suas subordinadas encarregadas da produção, do comércio e da cultura. (CASTELLS, 2009, p. 22 [tradução nossa]).

Depreende-se daí que o modelo hegemônico de comunicação numa sociedade está intensamente relacionado ao modelo hegemônico de organização sócio-política que nela se configura - o que permite entrever uma inter-relação entre modelos de comunicação e modelos sócio-políticos de uma forma geral. Mas hoje o potencial operativo das redes é outro, e assim como os hackers hackeiam o sistema hegemônico nas redes digitais, poderíamos dizer que o sistema hegemônico hackeou a dinâmica de rede - pois essa se tornou a mais eficiente forma organizacional na atualidade (ibid.; SANCHO, 2012, p. 92). Sendo assim, uma sociedade em rede não é necessariamente uma sociedade democrática ${ }^{193}$.

193 Segundo Galloway (2004), redes podem ser centralizadas, descentralizadas ou distribuídas. Na lógica dos novos ativismos aqui abordados, as redes podem ser classificadas como distribuídas 
Devido à imposição do caráter opressor da globalização, indivíduos e coletivos que se recusam a deixar-se absorver pela lógica dominante engendram formas de resistência no âmbito cultural. Para superar as problemáticas disputas que emergem da exploração globalizada, Castells acredita ser necessário desenvolver protocolos ${ }^{194}$ de comunicação, sendo este o preceito que constituiria uma cultura de sociedade de rede. Entretanto, não se trata de uma cultura que compartilhe valores (a não ser a comunicação como valor em si), e dessa maneira se sobrepõe às demais, mas justamente uma cultura de comunicação, que permita o diálogo entre as diferentes culturas em âmbito global, cada uma com seus valores. (CASTELLS, 2009, p. 37-8).

Contudo, será possível estabelecer tal diálogo em âmbito global sem preceitos básicos que garantam seu caráter democrático? Honneth (2003) se deparou com esse dilema ao tratar da luta pelo reconhecimento, e chegou à conclusão da necessidade de princípios abstratos universais que possam ser adaptados às realidades locais - $e$ revisados de acordo com os contextos históricos -, assim como Habermas (1989), que acredita que a ação coletiva democrática precisa ser guiada por uma consciência moral.

Enquanto os protocolos político-comunicacionais de Castells indicam a construção de acordos de convivência a partir de diálogos que trazem à tona a diversidade, Habermas vê no agir comunicativo uma prática que desvela o senso comum e, por meio da discussão lógico-argumentativa, propicia o entendimento mútuo. Trata-se de um agir guiado por discernimentos morais: o respeito às leis, por si mesmo, deixa de ser um imperativo ético, e a responsabilidade passa a ter outra conotação, não convencional, baseada na autonomia, pois "age moralmente quem age com discernimento" (ibid., p. 196). Tal suposição vai ao encontro do conceito de desobediência civil, colocado em prática pelos Anonymous, assim como por grande parte dos hackers e militantes sociais (SILVEIRA, 2010, p. 32).

(CASTELLS, 2013). Já as redes que hegemonizam o poder (id., 2009, p. 22) seriam centralizadas ou descentralizadas (estas, mesmo contando com centros de poder plurais, estariam submetidas a um poder central).

194 Galloway (2004, p. 7) aborda os protocolos sob a perspectiva do controle no ambiente digital e acredita que a resistência a esse controle também deve ser protocológica. De acordo com o autor, os protocolos governam o modo como "tecnologias específicas são acordadas, adotadas, implementadas e usadas pelas pessoas no mundo". Tal seria o sentido do hacktivismo: subverter os protocolos. 
É característico dos ativismos políticos desnaturalizar práticas convencionais e questionar códigos legais em nome da justiça. Mas a questão, a partir de Habermas, é até que ponto encontros e espaços que reúnem atores sociais em prol de causas comuns promovem discussões baseadas em informações compartilhadas, constituindo acordos democráticos por meio da argumentação racional de forma justa, livre e igualitária - pois o fato de afrontarem a moral dominante não significa que não constituam outras formas de autoritarismo e/ou senso comum. O mesmo se dá no meio digital, com as diferenças de que nele: supera-se a barreira presencial, o que aumenta as possibilidades de participação (mas ao mesmo tempo exclui os que não têm acessos as tecnologias digitais); é mais fácil atrelar argumentos a informações, pela facilidade que a busca online nos permite de pesquisar sobre determinado assunto (contudo aumenta proporcionalmente a dificuldade de verificação da validade das informações e acarreta outras limitações, como a fragmentação característica desse ambiente) (PAPACHARISSI, 2002).

A autora alerta que um novo espaço público não caracteriza uma nova esfera pública: o primeiro, promove discussão; o segundo, democracia (ibid., p. 11). Contudo, a revisão do próprio Habermas sobre sua teoria de esfera pública a flexibiliza, a partir do conceito de esfera pública parcial, que se divide em três tipos: esfera pública episódica, esfera pública de presença organizada e esfera pública abstrata (referentes a encontros cotidianos casuais, encontros organizados e troca de informações e ideias possibilitadas pela mídia, respectivamente) (LOSEKANN, 2009). As manifestações de junho mobilizaram essas três categorias de esfera pública parcial, e a comunicação via internet teve destaque nesse processo.

Conclui-se que apesar de não ser possível simplesmente substituir as instâncias políticas e a esfera pública pela comunicação via internet, como se isso por si só pudesse ter efeito democratizante, definitivamente ela é também constituinte do debate democrático e da práxis política contemporânea. Além disso, apesar dos movimentos sociais em rede não constituirem práticas democráticas ideais e de a internet não ser uma esfera pública em si, trata-se de um processo de experimentação e inovação rumo a uma outra democracia que não a instituída.

É preciso considerar também que a emoção tem um papel determinante no engajamento dos movimentos sociais em rede - e especificamente nas manifestações 
de junho (MALINI, 2013a; PELBART, 2013), como explicitam as críticas à ênfase de Habermas ao consenso democrático que destacam o papel do dissenso e daquilo que não é dito (colocando em xeque a centralidade do debate lógico-argumentativo), dos silêncios e afastamentos, dos conflitos e crises - que seriam importantes catalisadores de profundas mudanças -, assim como da inter-relação entre esfera pública e esfera privada e entre o que Habermas denominou "sistema" e "mundo da vida" (SANTOS, 1989, p. 152-5; HONNETH, 2003). Para Santos o "mundo da vida" habermasiano, que contempla as esferas privada e pública em contraposição ao sistema (Estado e mercado), "é o espaço e o tempo do consenso, da cooperação, da comunicação e da intersubjetividade", que sem dúvida são aspectos importantes e que devem ser ampliados e fortalecidos (ibid., p. 154). Mas não se pode ignorar a "tensão dialética com o conflito, com a violência, o silenciamento e o estranhamento [...], na maioria das vezes, latente, e essas últimas dimensões não aparecem à superfície senão de modo indireto e subjetivista, enquanto mal-estares, alienações, doenças, escapismos, insultos, desabafos, etc" (ibid., 154-5) - analogamente ao que Honneth (2003) traz à tona com sua teoria do reconhecimento.

Entende-se que com suas complexidades e contradições os movimentos sociais em rede constituem laboratórios democráticos - no aspecto local, de ocupação de espaços urbanos, mobilização e realização de assembleias populares, e no global, no que tange à interconexão de diversas lutas ao redor do planeta principalmente via internet - e mesmo que não incidam diretamente na democracia instituída, podem ser instituintes de novas formas de democracia (BRINGEL, ECHART, 2008). Defende-se a superação da dicotomia excludente entre emoção e razão nas análises das ações coletivas, pois esses dois aspectos perpassam a atividade social195, e a produção ou a ressignificação - de códigos culturais que se dá na luta por reconhecimento (HONNETH, 2003) precisa ser considerada na análise dos movimentos sociais contemporâneos que se articulam em rede, levando em conta que sua principal incidência e sua condição de visibilidade, para Melucci (1999, p. 87), corresponde à elaboração de significados alternativos sobre os comportamentos individuais e

195 Os autores destacam que no Brasil os estudos contemporâneos acerca dos movimentos sociais costumam dar ênfase aos atores que exercem influência principalmente no âmbito da institucionalidade, marginalizando as experiências de democracia radical (ibid., p. 465). 
coletivos.

\section{CONSIDERAÇÕES FINAIS}

Este artigo buscou tecer uma trama entre um apanhado de discussões relevantes para a investigação da atuação dos Anonymous nas manifestações de junho - passando por seu histórico, sua simbologia, sua dinâmica e seu potencial democrático. O tema é recente e complexo, mas seu impacto na práxis dos movimentos sociais e seu poder de contestação têm despertado o interesse da sociedade em geral e de pesquisadores, como pode ser percebido pela quantidade de material analítico rapidamente produzido sobre as manifestações de junho.

A ênfase desta proposta recai sobre a relação entre comunicação, cultura e política: como essa cultura que surgiu no universo online e dialogou com as ruas durante as manifestações de junho, que defende a horizontalidade e adota a lógica de rede sob anonimato, impacta no embate democrático. De acordo com Bringel e Echart (2008, p. 461),

\footnotetext{
a partir de uma hipótese compreensiva, é possível visualizar as dimensões mais esquivas à verificação empírica, mas que são fundamentais para a compreensão do objeto de estudo: intuições, práticas internas, convicções, subjetividades coletivas. Poder-se-iam analisar, assim, o sentido da mobilização, suas simbologias, práticas internas e sua incidência, nesse caso, na democratização.
}

Os autores entendem a análise dos sentidos como complementar à análise empírica, de modo a "abordar a realidade social como uma totalidade, manifestando seus antagonismos estruturais e suas contradições" (ibid., p.461). Tal sugestão dialoga com esta proposta: junto ao retrato desse ator mascarado, sua trajetória e subjetividade coletiva, será abordada sua atuação nas manifestações de junho - a popularidade da máscara-símbolo, a dinâmica da multidão e os clamores contra a representação política -, de modo a explorar temas sensíveis que são fundamentais para o debate político atual: a máscara e o anonimato (que, além de revelarem uma lógica identitária, permitem problematizar horizontalidade, representatividade e liderança), a relação entre a dinâmica de rede na comunicação e na política, o movimento entre o enfrentamento ao sistema hegemônico e sua cooptação por ele, bem como sua contribuição direta e indireta para a construção democrática. 
Novas formas de organização política evidentemente surgem. Elas carregam em si a ambiguidade de demandar transformações radicais mas, concomitantemente às resistências e inovações, reproduzir ideias e padrões de comportamento desse mesmo sistema contra o qual se revoltam - e do qual, mesmo que em oposição, fazem parte (como ocorre com qualquer movimento social, variando em cada caso a partir de seu contexto histórico, sua situação, suas opções políticas e sua capacidade de ressignificação). Entretanto, seu viés por vezes considerado anti-democrático (quando são acusadas de negar a representatividade e a liderança de modo irresponsável e de não apresentar um programa) pode ser uma importante pista para a compreensão do amplo descontentamento, principalmente entre os jovens, frente à democracia representativa - característica comum a diversos protestos e movimentos ao redor do planeta - e as alternativas político-culturais que se engendram.

\section{REFERÊNCIAS}

ANONYMOUS Brasil. Sobre. Disponível em: $<$ http://www.anonymousbr4sil.net/p/sobre.html>. Acesso em maio de 2013.

BEY, H.. T.A.Z.: Zona Autônoma Temporária. São Paulo, Conrad Editora do Brasil, 2004.

BRINGEL, E. Movimentos sociais e democracia: os dois lados das "fronteiras". Caderno CRH, Salvador, v. 21, n 54, p. 457-475, set-dez. 2008.

CASTELLS, M. Communication Power. Nova lorque: Oxford University Press, 2009.

Redes de indignação e esperança: movimentos sociais na era da internet. Rio de Janeiro: Zahar, 2013.

CHAUI, M. As manifestações de junho de 2013 na cidade de São Paulo. Teoria e debate, edição 113, 27 jun. 2013. Disponível em:

$<$ http://www.teoriaedebate.org.br/materias/nacional/manifestacoes-de-junho-de2013-na-cidade-de-sao-paulo?page=full>. Acesso em: junho de 2013.

COLEMAN, G. Anonymous: from the lulz to collective action. The new everyday: a media commons project. 2011. Disponível em:

$<$ http://mediacommons.futureofthebook.org/tne/pieces/anonymous-lulz-collectiveaction>. Acesso em: dezembro de 2013.

. Anonymous in Context: The Politics and Power behind the Mask. Internet 
Governance Papers. Centre for International Governance Innovation, n. 3, 2013.

FEBBRO, E. Anonymous e a guerra de informação digital. Carta Maior, São Paulo, 21 fev. 2012. Disponível em:

$<$ http://www.cartamaior.com.br/templates/materiaMostrar.cfm?materia id=19644>. Acesso em: jul. 2013.

FEIXA, C. Generación @: la juventud en la era digital. In: Nómadas, Universidad Central de Colombia, n. 3, 2000. Disponível em:

<http://dialnet.unirioja.es/servlet/articulo?codigo=3989394>. Acesso em: setembro de 2012.

GALLOWAY, A. Protocol: how control exists after decentralization. Cambridge, Massachusetts: MIT Press, 2004.

GOHN, M. G. 'Após atos, governo não tem interlocutores'. O Estado de São Paulo, São Paulo, 13 jul. 2013. Disponível em:

<http://www.estadao.com.br/noticias/nacional,apos-atos-governo-nao-teminterlocutores, 1053152,0.htm>. Acesso em: jul. 2013.

GUTIERREZ, B. La multitud brasileña no tiene nombre. El Diario, Madri, 26 jul. 2013. Disponível em: <http://www.eldiario.es/internacional/multitud-brasilenanombre 0 157834773.html>. Acesso em: julho de 2013.

HABERMAS, J. Consciência moral e agir comunicativo. Rio de Janeiro, Tempo Brasileiro,1989.

. Direito e democracia: entre facticidade e validade. Vol. II. Rio de Janeiro, Tempo Brasileiro, 2a ed., 2003.

HARDT, M.; NEGRI, T. Multidão: guerra e democracia na era do Império. Rio de Janeiro: Editora Record, 2005.

HARVEY, D., et al. Occupy: movimentos de protesto que tomaram as ruas. São Paulo: Boitempo Editorial, Carta Maior, 1a ed., 2012.

HONNETH, A. Luta por reconhecimento: a gramática moral dos conflitos sociais. São Paulo: Ed. 34, 2003.

INTERAGENTES. Cartografia de redes: um mapeamento das manifestações de 13 de junho de 2013. Interagentes, São Paulo, 22 jun. 2013. Disponível em: $<$ http://interagentes.net/?p=76>. Acesso em: junho de 2013.

LOSEKANN, C. A esfera pública habermasiana, seus principais críticos e as possibilidades do uso desse conceito no contexto brasileiro. In: Pensamento Plural. Pelotas, v. 4, n. 2, 2009.

MACHADO, M. Hacking como expressão do novo ativismo. In: Contempo. 
Campinas, vol. 4 , No 2, 2012.

Anonymous e zapatistas: um discurso afinado. 2012. Disponível em: $<$ http://murilomachado.com/anonymous-e-zapatistas-um-discurso-afinado/>. Acesso em: junho de 2013.

. Por dentro dos Anonymous. Santo André: UFABC, 2013.

MALINI, F. A Batalha do Vinagre: por que o \#protestoSP não teve uma, mas muitas hashtags. 2013. Disponível em: < http://www.labic.net/cartografia-dascontroversias/a-batalha-do-vinagre-por-que-o-protestosp-nao-teve-uma-mas-muitashashtags/>. Acesso em: agosto de 2013.

O que pode ser o \#ProtestoBR? post\#1. Disponível em:

$<$ http://www.labic.net/cartografia-das-controversias/o-que-pode-ser-o-protestobrpost1/>. Acesso em: agosto de 2013.

MARICATO, E., et al. Cidades rebeldes: Passe Livre e as manifestações que tomaram as ruas do Brasil. São Paulo: Boitempo Editorial, Carta Maior, 1a ed., 2013.

MARTÍN-BARBERO, J. Dos meios às mediações: comunicação, cultura e hegemonia. Rio de Janeiro: 2a ed., Editora UFRJ, 2003.

MELUCCI, A. Acción colectiva, vida cotidiana y democracia. México: El Colegio de México, 1999.

MOORE, A.; LLOYD, D. V de Vingança. Barueri: Panini Brasil, edição especial, 2006.

PAPACHARISSI, Z. The Virtual Sphere: the Internet as a Public Sphere. In: New Media \& Society, Londres, v. 4, n. 1, p. 9-27, 2002.

PELBART, P. P. "Anota aí: eu sou ninguém". Folha de São Paulo, São Paulo, 25 jun. 2013. Disponível em <http://www1.folha.uol.com.br/fsp/opiniao/119566-quotanota-aieu-sou-ninguemquot.shtml>. Acesso em: junho de 2013.

PIMENTEL, T.; SILVEIRA, S. A. Cartografia de espaços híbridos: as manifestações de 13 de junho de 2013. Interagentes, São Paulo, 11 jul. 2013. Disponível em: $<$ http://interagentes.net/?p=62>. Acesso em: julho de 2013.

SALLAS, A. L. F.; BEGA, M. T. S. Sociologia da juventude: releituras contemporâneas. In: Política e Sociedade, v. 5, n. 8, 2006.

SANCHO, G. R. Movimientos sociales y comunicación: la red como paradigma. In: Anàlise, n. 45, 2012.

SANTOS, B. S. Introdução a uma ciência pós-moderna. Rio de Janeiro, Graal, 1989. 
. Los nuevos movimientos sociales. In: OSAL - Observatório Social de América Latina, Buenos Aires, n. 5, setembro de 2001.

. O preço do progresso. Carta Maior, São Paulo, 2013. Disponível em $<$ http://www.cartamaior.com.br/templates/colunaMostrar.cfm?coluna id=6151>. Acesso em julho de 2013.

SILVEIRA, S. A. Ciberativismo, cultura hacker e o individualismo colaborativo. Revista USP, São Paulo, n. 86, p. 28-39, junho/agosto 2010.

SZANIECKI, B. Monstro e multidão: a estética das manifestações. Entrevista especial com Barbara Szaniecki. Instituto Humanitas Unisinos, 15 de julho de 2013. Disponível em: <http://www.ihu.unisinos.br/entrevistas/521910-monstro-emultidao-a-estetica-das-manifestacoes-entrevista-especial-com-barbara-szaniecki>. Acesso em: julho de 2013.

V DE VINGANÇA. Direção: James McTeigue. Estados Unidos da América/Alemanha: Warner Bros, 2006. 1DVD (132 minutos), NTSC, son., color. 